\title{
Network films and complex causality
}

\section{Maria Poulaki}

The 2008 film Burn After Reading (Joel Coen and Ethan Coen), aside from being a parody of the spy movie genre, can also be considered a complex film, which, as Erica Rowell puts it, 'depicts a chaotic world through a seemingly chaotic narrative'. ${ }^{\mathrm{i}}$ In this essay I use Burn After Reading as an illustration, a metaphor, and at the same time an exemplary case of the diegetic and structural complexity of network films, particularly when it comes to the issue of causality. I describe the network that Burn After Reading's multi-directional causal mechanisms create, and argue that these mechanisms make the film a complex system, whose parts not only form an intricate maze but are also causally connected in a nonlinear way.

As directors Joel and Ethan Coen note, Burn After Reading brings together two worlds, that of State employees in Washington DC and that of a fitness centre situated in the same city, whose characters collide. ${ }^{\text {ii }}$ At the start of the film, along with the opening credits, we see the US state of Virginia from a satellite camera, which gradually zooms in to 'land' on the headquarters of the CIA. There, an analyst responsible for the Balkan desk, Osborne (or 'Ozzie') Cox (John Malkovich) is called to the office of his senior, who tells him he is being demoted. The reason - his 'drinking problem' - seems to be well known among his colleagues; although Ozzie furiously denies it, citing instead political reasons and calling the demotion 'a crucifixion'. Disappointed and insulted, he decides to resign from his job, and goes home to make himself another drink. This is the first in a series of the film's many small ironic twists: the viewer soon learns to anticipate twists and turns, which contribute to the black comedic atmosphere characteristic of the Coens' work.

Ozzie decides to start writing what he thinks will be a 'pretty explosive memoir' about his experiences in the intelligence service; but his wife Katie (Tilda Swinton), a rather rigid pediatrician, appears not to share his enthusiasm. As the viewer discovers, Katie is secretly preparing to take divorce action against her husband, as she has been cheating on him with an-also married-US Marshal officer, Harry Pfarrer (George Clooney). When Katie hears that Ozzie has resigned his post, she decides to move more quickly: the last thing she seems to want is to sponsor her husband's nascent career as an unsuccessful writer. Her lawyer advises her that she should not forewarn Ozzie — a man professionally 
trained in deceit - about her intention to divorce him. Instead, she 'can be a spy too' and steal from him information about his finances while he is still unaware of her plans.

As noted above, alongside the world of state officials like Ozzie and Harry and their spouses, Burn After Reading encloses a second world, one that 'clashes' with the first: that of the fitness centre, Hardbodies. Intelligence, if not necessarily the strongest attribute of agents like Cox, is certainly the weakest link in Hardbodies. However, a piece of 'raw intelligence' is found 'lying on the floor' of the gym. It is the CD that Katie has managed to burn from the hard drive of Ozzie's computer, which contains not only details of his finances but also the memoir he has been writing, unbeknownst to her. Chad (Brad Pitt), a rather dimwitted personal trainer working at Hardbodies, is the first and perhaps the only person who appreciates Ozzie's memoir, not for its content but because of its author's affiliation with the CIA. Chad actually has no idea what the 'numbers and dates and numbers and shit' the CD contains mean, but he assumes they must be important. His colleague Linda (Frances McDormand) seems distrustful at first, but when Chad refers to the reward they might receive on returning the CD to its owner, is immediately hooked and starts plotting and arranging the strategic details that will help her and Chad make profit out of this 'once in a lifetime' coincidence. Linda is motivated by a desire to 'reinvent herself' with the aid of cosmetic surgery, and needs money for her procedures.

However, a midnight call from Chad and Linda to Ozzie fails to bring about the desired outcome (the financial reward that they hope to receive as 'good Samaritans'). When Ozzie assumes he is being blackmailed and becomes angry, Chad and Linda arrange to meet him to exchange his memoir for money. But the failure of this attempt as well decides Linda to proceed with 'plan B', and she and Chad find themselves at the Russian Embassy trying to sell the 'classified' information that has fallen into their hands to nonplussed diplomatic officials, who nonetheless - perhaps due to lingering Cold War reflexes - agree to look at the memoir before concluding that it is worthless. But Linda, determined to find the money for her surgeries, continues playing the spy, this time sending Chad to break into the Coxes' house to try and get more information.

Burn After Reading exemplifies the nonlinear causality characteristic of network films. The causal-logical narrative inferences the viewer is asked to make in the film become gradually dismantled. In the first half, we are continuously reminded, often in a comic way, that 'appearances can be deceptive', and we are primed for the surprises that ensue. For example, in an early scene a high-angle shot shows Ozzie lying on his sofa with his eyes open wide and a vacant expression on his face. Contrary to what the viewer might assume, Ozzie is not dead. He is actually in the process of recording his memoir, but 
lacks the necessary inspiration. He tries out many ridiculous phrases about the 'glorious past' of the CIA before jumping up and running downstairs on hearing the phone in the basement ringing. The call is for Dr Cox, his wife. The phone call perhaps raises Ozzie's - and the viewer's - suspicions that his wife has a lover. This is underscored in the next scene, in which Ozzie, watching a game show on television, hears the audience cheering 'she's married!; has a boyfriend!; she's pregnant!'; and also in a later scene, when before going out he decides to leave Katie a note, which - underscored by ominous music score - conveys a sense of unease or threat. In the note Ozzie mentions that he will be at the Princeton reunion dinner, but until we actually see him there, we are primed to infer that he is spying on his wife and her lover, since some unattributed POV shots suggest that the pair are under surveillance. Not only Katie's husband but her lover too appears secretive. Harry is preoccupied with a mysterious contraption in the basement of the house he shares with his wife Sandy: his secretiveness is accompanied by a suspicion that he is being tailed by a mysterious car.

Burn After Reading's play with the viewer involves the use of many 'surface POVs'. These are point-of-view shots representing what a character sees. Borrowing Gérard Genette's distinction between internal and external focalization, Edward Branigan notes that surface POVs form part of internal focalization, in contrast with other, 'deep' types of focalization, which reproduce the character's mental state. ${ }^{\text {iii }}$ Through the use of such POVs, the viewer of Burn After Reading has only external indications of what characters might be thinking, and so must draw his or her own narrative inferences. At the same time, the viewer often shares POVs that are not focalized (that is, their source remains unknown although they seem to be subjective) and have an ambiguous status. All the narrative inferences viewers are accustomed to making - and which this film promptsare left uncompleted when the 'second world' of Burn After Reading (that of Hardbodies and its characters) starts to interact with the first. As I will explain, this way the film seems to be making fun of the causal-logical structure of narrative itself.

Burn After Reading is 'intricately-plotted', according to a comment in the user reviews of IMDb, ${ }^{\text {iv }}$ or- to use the words of the CIA agents in the film, who try to follow the actions of the various characters- 'complicated' and 'fuzzy'. The two scenes involving a CIA official named Palmer reporting to his senior about the actions of the heroes are hilarious because of Palmer's apparent inability to articulate coherently what is happening. The CIA officials seem to be playing the role that dance played in ancient Greek tragedies - reflecting on what takes place while powerless to influence the action. These scenes, which follow the two most violent incidents of the film, are reminiscent of 
the stasima of ancient choruses. Alongside their summary of the action that has already developed, the emotional distance they offer from the atrocities taking place would normally, like the stasima, offer insight into the complexity of the characters' interactions and direct the viewer's attention to questions that are not yet answered. However, in Burn After Reading these scenes have the opposite result, as the CIA 'chorus' only leaves us more baffled than we were before. Whilst stasima aided the audience weave the narrative, offering a summary of the action so far by observing it from an external viewpoint, the CIA chorus proves rather useless in this role. In Burn After Reading, the construction of a causal-logical line of action is not particularly helpful, as this line is rather absurd overall; so the best the viewer can do is just follow the actors.

Of course, narrative hypotheses are always plausible and in fact are invited by the pseudo-mystery plot of Burn after Reading. At the same time, however, the film seems to make fun of the causal-logical cognitive approach, not just by undermining narrative expectations, but also by encouraging the viewer to reflect on their overall futility. The narrative of Burn After Reading frustrates any attempt to approach it cognitively, in a linear way: it is complex at the levels of both story and plot. Its plot develops by accelerating and augmenting the codependency of its separate elements - the actors and story threads it brings together. As the IMDb reviewer puts it: 'once the Coens start firing on all cylinders they never stop'. It is precisely the dynamic and 'uncontrollable' features of Burn After Reading that may be associated with its 'network' properties.

Burn After Reading can be characterized as narratively complex, along with numerous post 1990s films, ${ }^{v}$ from Pulp Fiction (Quentin Tarantino, 1994) to Cloud Atlas (Tom Tykwer and Andy and Larry Wachowski, 2012), and its complexity is expressed particularly through the dimension of causality. A feature that stands out and arguably affects causality in many films with complex narratives is the increased-in comparison with other Hollywood narratives - number of characters. In his taxonomy of the 'Tarantino phenomenon', as he calls the post 1990s complex narratives, Charles Ramírez Berg refers to recent films with multiple characters and multiple stories. His contention is that the majority of 'alternative narrative films', such as Pulp Fiction, Magnolia (Paul Thomas Anderson, 1999), Code Inconnu (Michael Haneke, 2000), 13 Conversations about One Thing (Jill Sprecher, 2001), Crash (Paul Haggis, 2005) and others are distinguished by an excessive number of protagonists. ${ }^{\text {vi }}$ A special category of multipleprotagonist (or 'ensemble') films that Ramírez Berg distinguishes has what he calls 'hub and spoke' plots, combining a large number of characters with a complex - in terms of time and causality — narration. In hub and spoke plots — such as, for example, Alejandro González Iñárritu's Amores Perros (2000) and 21 Grams (2003), 'multiple characters' 
story lines intersect decisively at one time and space'. vii The intersections of characters in time and space emphasize the role of chance events and contingency. According to Ramírez Berg, these plots

Thematically [...] demonstrate the frailty of agency by presenting a world where happenstance prevails and best-laid plans come to naught. At a formal level, they question whether causality and characters' choices, the bedrocks of Hollywood's classical narration and narration in general, are viable as narrative mainstreams particularly in contemporary dramas and romances. And because causality is foundational not just for movies but for life, particularly American life, the ideological implications of such challenges are seriously subversive. ${ }^{\text {viii }}$

Problematising causality and experimenting with non-causal connections between events, ensemble and 'hub and spoke' plots have many similarities with David Bordwell's category of 'network narratives', as he calls the strand of narratively complex films in which a multiplicity of separate characters are connected through chance. ${ }^{\text {ix }}$

Bordwell proposes the term network narratives to address the most recent revival of multiple protagonist films. According to him, the format of network films 'crystallized in the 1980s [with directors such as Robert Altman, Jean-Luc Godard and Otar Iosseliani being among the first who experimented with it] and was revivified in the 1990s', with films such as Short Cuts (Robert Altman, 1993), 71 Fragments of a Chronology of Chance (Michael Haneke, 1994), Chungking Express (Wong Kar-Wai, 1994) and Pulp Fiction. ${ }^{\mathrm{x}}$ But is character multiplicity a sufficient condition for plot complexity? Bordwell points out that the aggregation of characters in network films makes the plot 'more complex', ${ }^{\text {i }}$ as the intersections between them are not obvious from the beginning nor easily established through preexisting relations, and thus need to be built gradually, making use of various plot contrivances. Because of the intersection of strangers involved in these films, Bordwell regards them as expressions of lay interpretation of network theory (as in 'six degrees of separation') and products of exchanges between network/chaos theory and popular imagination. To explain the use of the term 'network' in his description of contemporary multi-protagonist films, Bordwell refers to the sociological model of networks developed after the 1950s 'small world' experiments of social psychologist Stanley Milgram. According to this model, networks are composed of links between individuals, which in social network theory are personal acquaintances. ${ }^{\text {xii }}$ Apart from this increasing awareness of social networks other cultural factors, among them rising internet literacy, contributed to the cinematic wave of network narratives in the mid-1990s. xiii 
The network is composed 'when strangers intersect', and chance is what drives their intersections, no matter how goal-oriented characters' individual trajectories may be. In network narratives, Bordwell notes, 'The plot structure [...] must find ways to isolate or combine characters in compelling patterns that will replace the usual arc of goal-oriented activity. The principal source of these patterns [...] is chance'. ${ }^{\text {xiv }}$ If coincidencecontingent events and encounters, circulating objects, accidents and internet friendshipsis what makes people meet (or even kill each other, as in Burn After Reading), does causality play any role in network narratives? And if so, what forms does it take? At the micro-level, causality in many complex films is distributed across an intricate network of characters. Beyond the level of individual actors, though, the role of 'transcendental' factors, such as chance and contingency, often, as already suggested, takes a central place in these films, making the overall causal patterns less anthropomorphic.

Bordwell takes up the issue of causality in his discussion of network narratives. He uses the term 'loose causality' - meaning an absence of tight cause and effect sequences - and finds it a distinguishing characteristic of network films - discussing in detail Nashville (Robert Altman, 1995), Magnolia, Les Favoris de la Lune (Otar Iosseliani, 1984) and Les Passagers (Jean-Claude Guiguet, 1999). In network films characters' lives, which are rather autonomous, eventually meet and separate, not because of the characters' purposeful actions but as an outcome of pure chance. This loose type of causality in network narratives does not preclude expressions of the traditional Aristotelian character-driven causality in them. All characters might have their own goals (for example in Crash, Cloud Atlas, or indeed in Burn After Reading), but this does not prevent contingency from changing their lives in unpredictable ways.

Bordwell's observation of 'loose causality' in contemporary complex films is valid in the sense that many events in network narratives 'just happen' and are not attributable to an 'overarching causal project'. ${ }^{\mathrm{xv}}$ However, Bordwell does not elaborate on the characteristics of this loose causality, which is mostly negatively defined. Calling the causality of a group of complex films 'loose' implies a presupposition that causality is tight. This form of 'tight' causality has been considered characteristic of classical narrative cinema, in which:

Events in the story are typically organized in a relationship of cause and effect, so that there is a logic whereby each event of the narrative is linked to the next. The classic narrative proceeds step-by-step in a more-or-less linear fashion, towards an apparently inevitable resolution. ${ }^{\text {xi }}$ 
This cause and effect logic in classical narrative cinema needs to be supported, on the one hand by temporal and spatial coherence, ${ }^{\text {xvii }}$ and on the other by agents - most of the time one central hero - presented as 'fully rounded individuals' with well-developed personality and corresponding motivation. It is against this backdrop of tight characterological causality that the 'loose causality' of network films is defined. Bordwell's evaluation of causality in network films is made using classical narrative and anthropomorphic standards - the latter in the sense of events caused by human actors and bringing forth other events as consequences of previous actions. This is a definition of causality based on the Aristotelian model of drama.

In Bordwell's theorization of network narratives in cinema, chance and contingency appear to succumb to predestination, in that the chance events that proliferate in these films are interpreted as ultimately serving the overarching causal line of the plot, which intradiegetically often takes on the appearance of destiny. That is why Bordwell and other commentators see a transcendental element in the prevalence of happenstance in complex films. The intervention of chance as a transcendental factor makes the connections between characters appear almost 'metaphysical' and, according to Silvey, tending towards a kind of totality. ${ }^{\text {viii }}$

The tendency of network narratives towards the transcendental echoes the 'melodramatic imagination' that Peter Brooks traced in literature, from Balzac and James to Proust and Lawrence, who refused the notion that 'that the world has been completely drained of transcendence'. ${ }^{\text {xix }}$ The 'melodramatic ethos' and its interaction with the complex narrative structure has been discussed by Maria del Mar Azcona Montoliú in the context of multi-protagonist films such as Iñárritu's 21 Grams. ${ }^{x x}$ As Montoliú notes, in 21 Grams 'characters' desires are also part of the emotional continuum running through the film even if, within the context of the multi-protagonist genre, they seem more a consequence of the context than the fullest expression of the subjective and individual drives of human beings'. This emotional continuum in 21 Grams (and in other network films) transcends the hero's individuality and yet remains immanent in the film's - and its diegetic world's-structural network.

What, however, is the relationship between chance and causality? Can chance cause and be caused, without being a transcendental element? Indeed, chance is a system of causation in its own right, considered as such especially since the end of Enlightenment, and works of contemporary narratology acknowledge its causal power. ${ }^{\text {xxi }}$ In literary works as old as Aphra Behn's The Lucky Chance (1686), as well as in the network narratives of contemporary complex films, chance is a cause, but at the same time it disrupts causality in the sense of one-to-one relationships between events as causes and 
effects. A chance event might start a chain of causality but cannot itself be explained as the result of a pre-existing cause. It thus becomes hard to establish any chain of causality when there is, not just one but a proliferation of chance events within a text. The central role network films ascribe to contingency can now be highlighted in its tension with the type of causality that defines narrative.

Many complex/network films develop around the effects of chance events. However, here the effects do not correspond to their causes by logical necessity, neither are they exclusive. The same contingent event may have entirely different outcomes. The multiplicity of characters in network films is particularly functional in illustrating the complex effects of chance. For instance, in Code Inconnu the same contingent event, a pastry bag discarded by one character, affects the lives of all the other characters, but with very dissimilar outcomes depending on the character it affects. Chance has an organizing power that interacts with the pre-existing organization of the world upon which it exerts its influence. Perhaps coincidence is governed by a design, as Bordwell seems to imply, ${ }^{\text {xxii }}$ but it does not ultimately succumb to this design: it rather transforms it into a new structure.

But to what extent is causality in complex films exceptional, it might be asked, given that loose causality may also be a feature of more conventional narratives? Seymour Chatman differentiates between causality and its looser form which, borrowing the term from philosopher Jean Pouillon, he calls contingency:

In traditional narratives, the internal or story logic entails the additional principle of causality (event $a$ causes $b, b$ causes $c$, and so on) or, more weakly, what might be called 'contingency' ( $a$ does not directly cause $b$, nor does $b$ cause $c$, but they all work together to evoke a certain situation of state of affairs $x) .{ }^{\text {xxiii }}$

Contingency, which blurs the initial causes of events, though to some extent contained in all narratives, is more noticeable in unconventional ones, such as Robbe-Grillet's paradigmatically non-linear literary texts. As Chatman notes: 'The idea of contingency is attractively broad, for it can accommodate new organizing principles' ${ }^{\text {xxiv }}$ In contemporary complex films these new organizing principles become, I would argue, much more pervasive, challenging traditional forms of narrative organization.

Contingency, as in other network narratives, plays a crucial role in Burn After Reading. To begin with, the CD containing Ozzie's memoir falls from the bag of the secretary of Katie's lawyer at the gym. We never witness this incident, but are asked to infer it later, while we have already been wondering about the missing link: how did the CD that Katie burned end up 'lying on the floor' of Hardbodies? A certain irony lies in the striking 
difference in the way the incident of the lost and found CD is valued by the different parties involved. The secretary's reaction when she realises she has lost the CD contrasts with Chad's when he finds it: she duly reports its loss to her boss and begins to burn another copy from the hard drive of her computer. The difference in the way the 'two worlds' of Burn After Reading respond to the same object becomes even more ironic in retrospect, when one considers the final outcome of a contingent-and for some characters totally unimportant-incident: a CD falls into the wrong hands and this has among its consequences two characters in the film being killed, another ending up comatose in hospital and a fourth escaping the country in a paranoid condition.

If we consider the separate characters as basic elements or 'nodes' of the textual network of Burn After Reading, it s apparent that this network develops nonlinearly in both space and in time, through the interactions between the elements. On the one hand, in space a 'small-world effect', as it is called in network theory, is in the making. In dynamic network science, which is a strand of complex systems theory, a small number of random links added to a regular network 'can generate a very large effect', turning it into a 'small-world network'. This happens because the 'average path length' (which is defined as the number of links between two nodes in a regular network) is reduced to half with the first five random rewirings (connections). ${ }^{\mathrm{xxv}}$ Therefore, once a long-distance link between two people is achieved, more of their mutual acquaintances become connected with each other. In simple terms, the fact that most people are 'more likely to be friends with the friends of [their] friends than with other, random, people, ${ }^{\mathrm{xxvi}}$ is a result of the small-world network property. In Burn After Reading, as soon as one random (longdistance) link connects the two worlds as the CD of one State official is found in Hardbodies, then the connections become more, develop faster, and ultimately have disproportional effects as the system develops in time. In the course of the film, Harry comes across Chad and Ozzie meets not only Chad and Linda but also Ted-in the latter case with lethal consequences. Also, at another, global, level of the small-world effect, Linda and Harry, though unknown to each other at the beginning of the film, eventually meet through internet dating. In all these cases the encounter of the two worlds, the one of the government officials and the other of Hardbodies, is directly or indirectly mediated by information - contained in a CD or in a dating site. The 'accident' of the loss of the CD with Ozzie's memoir would not have extreme consequences if the relations between the various characters did not start increasing in number and complexity. Contingency therefore leads to structure, as random links end up organizing a complex system. Information plays an important role in the emergence of Burn After Reading's network. However, it is not the information that some characters have been trying to steal - that 
contained in Ozzie's memoir, or in his financing files - that is the most significant. Rather, information is created out of the interlinking of the characters' actions, which neither the CIA (at the intradiegetic level) nor the viewer (at the extradiegetic one) can foresee. According to the mathematical definition of information, the lower the possibility of a selection indicated, the higher the number of informational bits contained in a message. ${ }^{\text {xxvii }}$ Burn After Reading's plot gradually acquires high informational value because of its procession through the improbable choices and - seemingly — nonsensical actions of the characters once their 'two worlds' meet in one 'small world'. Moreover, the way information is 'passed on' and acted out rather than being cognitively processed, makes the characters of the film look more like informational vessels than psychologically rounded entities. As Evan Smith observes of Pulp Fiction, 'psychological transitions might be the greatest weakness' of 'thread structure' films. ${ }^{\text {xxviii }}$

The multiplicity of agents that network films involve is arguably a means through which linear causality is undermined and other types of organization become prominent. The application of emergent and bottom-up approaches to film's textual and cognitive organization, like those adhered by complex systems theory and its applications, could prove useful when the lines of causality as traditionally conceived in film narrative theory are broken. Complex systems scientist Stuart Kauffman has shown how complexity is built in multi-agent and densely interconnected systems. ${ }^{\text {xxix }}$ These two factors, the number of agents and the density of connections, are interdependent, as the large number of individual units increases the possible interactions and therefore the complexity of the resulting system. Ashok Sengupta notes that in fact these two factors are the prerequisite for complexity:

In the vision proposed by complexity, we can identify forms and evolutive characteristics common to all, or almost all, systems that are made up of numerous elements, between which there are reciprocal, nonlinear interactions and positive feedback mechanisms. These systems, precisely for this reason, are generally called complex systems. ${ }^{\mathrm{xxx}}$

Moreover, as anthropologist and neuroscientist Terrence Deacon notes,

With every iterated interaction, relational properties are multiplied with respect to each other, so an increase in numbers of elements and chances for interactions increases the relative importance of interaction parameters and related contextual variables. $^{\text {xxxi }}$ 
Films with network narratives follow this complex-systemic logic: by increasing the number of agents they also increase the relational range and complexity of the network that these relations form.

Bordwell refers to network narratives in cinema as 'catalogues', ${ }^{\text {xxii }}$ because the separate stories they contain (through the different characters) stay for the most part discrete in these films, and actually function in the mind of the viewer as alternatives according to some common criterion. A catalogue is not a system but a list of elements; the formation of a system requires relations between them. I would argue that one of the ways in which network films communicate with the viewer is the cognitive and affective experience of the process through which a catalogue, or a heap, becomes a system. The absolute disentanglement of elements that a heap suggests would abolish a film's communicative potential. As the systems philosopher Ervin Laszlo points out: 'If subsystem communication is reduced to zero, the whole system has zero level of organization; i.e. we are dealing with a limiting case in which the whole system ceases to be a system and becomes a heap of independent components'. ${ }^{x x i i i}$ Thus, in systems theory, it is the communication between elements, or system components, that makes a system (a 'constitutive complex' in Laszlo's terms) distinct from a heap (a 'summative complex'-in which the components are just added to one another without being indispensible for the system's constitution): 'the more two or more components communicate, the more information they pass to one another, and thus the more they determine each other'. ${ }^{\text {xxiv }}$ In network films, the flow of information and communication increases gradually as the separate agents and story components are interlinked and begin to create a collective organization - that is, a system. This interlinking is not the same intense in all network films, nor does it always happen the same soon; however, it is always present, even as a possibility in the films Bordwell calls 'borderline cases' of network films; without it, the films would cancel their communicative potential.

As already broached, in the case of Burn After Reading, the characters function as informational vessels, passing on the information they receive (the $\mathrm{CD}$ being a diegetic actualization of this information) without cognitively processing and understanding it. But through the connections and interactions between characters/agents - who are at the same time basic diegetic components - entailed in such handling of information, the diegetic information becomes systemic information at the extradiegetic, 'formal' level of the film. Thus the film becomes a constitutive complex. The complex systemic framework allows us to see the diegetic interactions as primarily informational and secondarily anthropomorphic/characterological. Moreover, it shows how the structure 
that these interactions create at the level of the film's form is not closed and symmetrical but open and nonlinear.

Network narratives, as already noted, include a multiplicity of characters, who take on more or less equal parts of the narrative time and agency. By focusing only on the number of characters, however, the adjective 'network' offers no more information than the older label of 'ensemble' or 'multi-character' narrative, a common trope also in other media products, such as television soap operas and other serial narrative formats. A network is not a sum of individuals: it is a system so long as links connecting the individual nodes organize them into one collective organization. It is the entanglement of the units in time that makes a network — and a network film-complex.

Recent dynamic approaches to networks as complex systems emphasize not only their small world effects but also their nonlinear development as complex systems in time, through the relations developed between their components, which make them, in Laszlo's terms, constitutive complexes. In Burn After Reading, for example, each action of one element — narrative 'actor' or agent — of any of the two worlds of the film's plot has in most cases a disproportionate - and in this sense 'nonlinear' - impact on the other elements, regardless of which of the two worlds it inhabits. For example, in the long run Osborne Cox's demotion has the indirect consequence that Linda's cosmetic surgeries are paid by the CIA. The initial actant (the CIA) is affected - though indirectly and in a nonlinear fashion - by the consequences of its decisions. The feedback CIA ultimately receives might be negative (as the senior official concludes, 'I guess we learn not to do it again'), but it has passed through a chain of both positive and negative feedback between the various elements, a chain similar to that involved in most complex systems, as Magoroh Maruyama, the pioneer in the study of feedback, has shown ${ }^{\mathrm{xxxv}}$ In mutual causal systems - or feedback systems - the activity of each element of the system has an impact upon the other elements and, in turn, upon themselves. Feedback can be negative (a communication that helps a system to maintain a stable state called homeostasis) or positive (a communication that leads the system to a continuous and cumulative deviation from its initial state, thus to a certain disorganization). Self-organizing systems usually take the form of feedback networks which combine negative and positive feedback. And this type of feedback increases the complexity of systems through co-dependency of the parts, mutual causality and amplification of deviation.

An updated conception of networks as complex systems would be required in order to understand the complex function of causality in network films. Wendy Everett seems to be pointing at this direction of complex systems theory, and particularly chaos and network theory, as adequate frameworks for a theoretical approach to such films as Free 
Radicals (Barbara Albert, 2003), Run Lola Run (Tom Tykwer, 1999), Code Inconnu, Amélie (Jean-Pierre Jeunet, 2001), and Intermission (John Crowley, 2003)—films Everett prefers to call fractal:

What is new about today's understanding of networks, and what makes it impossible to approach them with simple linear graphs (in mathematics or physics) or with straightforward linear narratives (in films or novels), is the recognition of their essential complexity. Complexity is characterized by variety, heterogeneity, and the fact that the various elements in a compound behave in random and different ways. Networks are complex systems because they exist by interacting; and they are dynamic because they evolve and change in time, driven by the random activities or decisions of their very components. ${ }^{\text {xxvi }}$

At the intersection of network theory and complex systems theory, accidents (even accidents like the one created when a CD falls into the wrong hands) can be regarded as (external) bifurcations that may cause positive feedback in a network system. As Maruyama notes: 'all processes of mutual causal relationships that amplify an insignificant or accidental kick build up deviation and diverge from the initial conditions'. ${ }^{\text {xxvvii }}$ Even though our main example of Burn After Reading is certainly not thematically influenced (like certain other recent films-The Butterfly Effect (Eric Bress and J. Mackye Gruber, 2004) would be an obvious example) by chaos theory, it seems nonetheless marked by the specific nonlinear workings of causality in complex networks, where a small event leads to disproportional outcomes. To understand how agency and causality work in Burn After Reading we can trace how the film's system develops from an initial state (no relations or just beginnings of relations between characters) through the intensification of these relations.

Two interwoven levels of causality are distinguishable in the plot of Burn After Reading. The first is the micro-causality of the characters deriving from their individual motives. The second level is the macro-causality of the network that their interrelationships make. At the micro-level, causality appears individualistic, anthropomorphic and perhaps cynical, whereas at the macro-level it appears transcendental and omnipresent, surpassing the individualism of the characters and connecting them in unexpected (and catastrophic) ways. So far these two levels tend to be kept apart in the theorization of network narratives.

At the level of micro-causality of Burn After Reading, the 'internal organization' of each character, his or her expectations and motives, will certainly influence but not—as it ultimately becomes obvious - decisively determine, the output of their interactions. In the 
course of the film we come to infer these motives: Chad is fascinated with the 'raw intelligence' he has discovered and seems to be simply enjoying the probability that perhaps for the first time in his life- he and intelligence can meet. Linda desperately wants to reinvent herself and her body as well as find a boyfriend with a sense of humour. Ted is secretly in love with Linda and is persuaded to help her in her groundless plot. Harry is a hedonistic character who enjoys casual sex, remaining nevertheless dependent on his wife, immature and incapable of assuming responsibility of any kind. Sandy wants to get a divorce and get rid of her untrustworthy husband. Ozzie is full of rage and bitterness against the 'morons' who, unable to acknowledge his mental superiority, have always been bothering him. Katie wants to keep her finances intact and stay in control, and away from her 'loser' husband.

Individual character motives and reasons create causal patterns (the manipulative motivational pattern of the film's women and the paranoid one of the men), which in turn contribute to the overall causality of the film's network - which, however, cannot be attributed or reduced to any single agency in particular. Even though it is the motivations of individual characters that seem to be triggering some of the 'actings out' taking place in the film, no single character, not even the most intelligent or manipulative of them, is in a position to predict the range of the consequences of their actions' co-resonance.

As in other network films, once individual motives and characters from the two separate worlds of Burn After Reading become intensely linked and co-resonate with one another, the film's narrative system goes through a 'phase transition' which, in complexity theory, happens when different units of a system resonate together. ${ }^{\text {xxxviii }}$ This co-resonance gives the system unpredictable properties ${ }^{\text {xxxix }}$ and has augmented effects on its individual components. When a different, higher, level of causality emerges in Burn After Reading once its dynamic network is formed, the characters' desire to control the course of the events (or to escape from being controlled) is rendered futile. Even though each one is given some sort of 'internal' motive, as already noted, the events that follow cannot be seen as linear and logical consequences of any of the particular motives, or even less traced back to any one of them. The prevalence of nonlinear causality in Burn After Reading makes it a dynamic system, a system found in a 'transient process': strictly speaking, all real systems are dynamic systems. However, when the duration of the transient process is negligibly small compared to the duration of the investigated phenomenon, and where the nature of the transient process does not have an important influence on the behaviour of a system, it is not necessary to take into consideration the dynamic properties of the system under consideration; it can 
be assumed that the changes in state follow instantaneously the causes which produce them. ${ }^{\mathrm{xl}}$

In network films, though, the interactions between characters and the network they create do have an important influence upon the way their individual trajectories develop. But this influence is nonlinear and not easily attributed to any of the individual agents. Thus, if a network film is seen as a diegetic network/system, the dynamics of this system make a cause-effect matching implausible. It is important therefore to 'take into consideration the dynamic properties of the system' and see what transformations they bring about.

Even if the individual motives of actors in Burn After Reading may be recognizable, the co-resonance of a number of agencies in the network of the diegesis is not foreseeable. The network's 'macro-agency' is the contribution of every single microagent to the network that connects them to all other agents, making their ensemble evolve in nonlinear and unpredictable (from the micro-level perspective) ways. Through the emergent movement from the micro and singular to the macro and global, and from units of agency to aggregates, the anthropomorphism of network narratives meets the 'elemental' - as Galloway and Thacker characterize it ${ }^{\text {xli }}$ - nature of complex networks and their dynamics, suggesting a shift from human to nonhuman (or systemic) ways of conceiving agency and causality in complex films. Complex films' networks of human and nonhuman agencies develop as systems through 'infinitesimal perturbations', which make the story's progression nonlinear-impossible to go back to its initial state due to the constant increase of complexity, and also impossible to deduce from one single perspective. It is this emergent system that is often explained, diegetically or hermeneutically, as 'fate', and lends these network films their transcendental allure.

But how can we speak about contingency and systemic 'emergence' in any narrative that is ultimately its narrator's construction? How can a film's plot acquire its own macro-causality? Arguably, we cannot proceed with the complex systems framework without reconsidering the placement of the narrator or 'auteur' in the position of the ultimate 'cause'. Contingency is a key factor in complex networks, and is clearly also an element that fascinates filmmakers. The Coen brothers' interest in the contingent and unexpected is reflected in their preference for 'idiotic' characters, like Chad and Harry in Burn After Reading. As Ethan Coen has explained, 'a lot of our movies are about dolts. [...] Maybe it's just because it seems to go somewhere in terms of the story. If everybody knows what they are doing in the movie, if they are capable, and everyone is on top of things then what is going to happen that is interesting or fun, or surprising? ${ }^{\text {, xlii }}$ Like all other filmmakers, the Coens of course set the parameters for the film to develop-and in 
the particular case of Burn After Reading to develop in a complex way. However, they themselves admit to have been taken over and guided by coincidence in this film, letting go of control to some extent: 'I guess we sort of wanted to do a spy movie. It didn't exactly turn out that way. I don't really think it is a spy movie. That's how the original idea was structured. ${ }^{\text {xliii }}$

In this sense, the Coens' approach brings to mind that of scientists simulating complex systems, following an 'agent-based' methodology. In computation, agent-based models, also referred to as 'multi-agent approaches', are used in order to simulate the various actors in a social or natural system and to make it easier to understand how a complex system develops from the micro to the macro level. ${ }^{\text {xliv }}$ The behaviour of agents is bottomup and unpredictable, however, and its tracking helps scientists understand how linkages and aggregations of agents lead to moments of phase-transition and emergence of systemic behavior. The agent-based stance of the Coens is perhaps reflected in the behaviour of the CIA in Burn After Reading: following the agents, tracking their moves, and keeping a record of emergent incidents; abandoning the need to understand the motives of characters (classical narrative approach), but still managing to keep them under control.

To conclude, the degree of codependence of components in network films, from Nashville and Code Inconnu to 21 Grams and Magnolia, increases because of the greater spatial disparity of information across different plot threads and agents, none of which has control. The respective lack of information characterizing each actor/unit of narrative agency makes connectivity and communication between units necessary, and through the increase of connectivity the units form a system. At the structural level of complex films, the co-dependency of both characterological and narrative elements (agents and actions/events) increases through interconnections. This structural or formal motion influences the story as well, creating causality of a kind different from that characteristic of the classical conception of narrative. Complex causality may be better conceived as a cumulative, nonlinear and emergent effect rather than as an event-sequence of causes and effects. While this applies to all network films, Burn After Reading is an exemplary case, as it self-consciously thematizes information and control, as well as the chaotic trajectories that a network system may take under perturbations.

Complex network films display a multidirectional and multilevel causality that can be seen as the product of a feedback circuit that connects, in the same network, the agencies of different actors/actants across different diegetic levels. At the intradiegetic level, a complex network film brings together and 'interlocks' - through parallelism or 
crosscutting - separate agents and, along with them, their individual viewpoints upon the story world. It is not just the number of characters but the connections between themand the way the connections are made - that become prevalent. What brings characters together might be chance, but the result of their interactions cannot be attributed to chance alone; rather, it is the emergent (but not transcendental) product of their relations. Chance itself is caused by relations, as contingency seems to be triggering further contingency. A proliferation of chance events in a film is incompatible with classical narrative causality, because chance cannot be easily attributed to one single cause: it can, however, be attributed to the synergy of many causes and causal agents, and this may bring about unexpected consequences.

Network films derive their dynamics from connections - on the one hand between a multiplicity of autonomous agents and on the other between different diegetic levels produced by these relations. Thus, from the micro-level of characters we move to the mid-level of their complex constellations and the macro-level of system (or formal) dynamics. Following the logic of agent-based methodologies used in simulations of complex systems, an 'agent-based' approach to film narrative analysis would allow for the establishment of a multi-directional feedback circuit between the various narrational levels.

Referring to such simulations, computer scientist Pierre Marcenac distinguishes between 'micro-agents' who lack knowledge of global constraints, 'medium-agents' who model the interactions of micro-agents and who feed back (through a process called 'back-propagation') upon the micro-agents' behavior, introducing constraints to it, and lastly 'macro-agents' who observe self-organization and 'generate' the medium-agents that model it. ${ }^{\text {xlv }}$ Applying this model to network films, the micro-diegetic level of characters and actions gives way, through complication of relations and nonlinear causality, to aggregates of agency at the mid-level, the patterns of similar behaviour discussed earlier. Mutual causal processes take place across levels. On the one hand, higher-level 'medium-agents', who are aggregates of individual units/micro-agents, feed back into the micro-agents. This can be seen not only in network films like Burn After Reading, but also in Babel, Crash and Code Inconnu, in which, from a certain point on, all characters are affected by the connections created between them, which influence both their individual trajectories as characters and the overall structure of the plot. Thus, the mid-level of interconnections on the one hand introduces constraints to the micro-level, affecting the micro-agents, and on the other hand contributes to the overall structural transformation, taking place at the (extradiegetic) macro-level, of the text into an organization that acquires a causality_or agency — of its own. Causality in complex 
films operates across all three levels and is distinguished by virtue of its emergent properties, both from character-based causality and from a linear and 'Newtonian' (in the sense of cause-effect sequences that resemble billiard balls hitting each other) conception of causal narrative structure.

Recent approaches to networks as complex systems focus particularly on the dynamic properties of networks. ${ }^{\text {xlvi }}$ What attracts the attention of network scientists is not only the shape and spatial distribution of connectivity, but also its dynamics as the network selforganizes and develops in time as a complex system. Causality cannot be bracketed out from accounts of how a network system comes into being and evolves out of the separate elements/nodes that compose it. A network is not caused by the individual actions of its elements, nor by a single transcendent and overarching cause or motivation; it rather emerges as an organization of a multiplicity of agencies and their complex relations. This organization acquires a systemic causality which, through a feedback process, in turn influences the units that now participate in the collective organization. Thus, I would argue that in complex films such as those containing networks of characters it is not just that 'contingency replaces causality', xlvii but rather that a qualitatively different form of network causality is at work-one that couples with contingency rather than excludes it. Every complex system evolves in constant exchange with contingency, and achieves its organization through an interplay between contingency and structure.

The complexity of multi-character network films - the interactions and relations between their components, as well as their evolution in time- has not been sufficiently addressed in film studies. A shift of theoretical and methodological focus, from (classical) narratology to complex systems theory, is required in order to gain insight into the issues of causality involved in these films. Complex systems theory, and its application to the study of networks, offers useful tools in thinking of how the organizing principle of causality, the cornerstone of narrative, is subordinated to a 'new organizing principle', which in complex systems theory is emergence. Networks are dynamic complex systems that acquire causality as they emerge out of the links between units. Thus, causality in network films is not loose but complex and nonlinear. And its complexity, much more than the entanglement of the cause-and-effect chain, suggests the emergence of new causal dynamics at the macro-level.

\footnotetext{
i Erica Rowell, 'Burn After Reading: film review', Film International, vol. 37, no. 1 (2009), pp. 74-77.
} 
ii Interviewed by Rebecca Murray, in 'Joel and Ethan Coen discuss Burn after Reading', About.com guide, <http://movies.about.com/od/nocountryforoldmen/a/countryjc111307_2.htm>. Accessed 25 January 2014.

iii Edward Branigan, Narrative Comprehension and Film (New York, NY: Routledge, 1992), pp. $112,179$.

iv The comment, reproduced from the website <prejudicemadeplausible.wordpress.com>, appears under the title 'The Coens' funniest film since "The Big Lebowski"' in the IMDb user reviews for Burn After Reading (posting date 12 September 2008).

${ }^{v}$ For an overview of complex narratives in cinema and their theorization, see indicatively: the contributions of David Bordwell ('Film futures') and Edward Branigan (Nearly true: forking paths, forking interpretations') in Substance\#97, vol. 31, no. 1 (2002), pp. 88-104 and 105-114 respectively; the 2006 special issue of Film Criticism (vol. 31, no.1/2) 'Complex Narratives' edited by Janet Staiger; the 2006 The Velvet Light Trap's issue (vol. 58, no. 1) 'Narrative and Storytelling'; Bordwell's The Way Hollywood Tells It: Story and Style in Modern Movies (Berkeley, CA: University of California Press, 2006); as well as Warren Buckland's edited volumes Puzzle Films: Complex Storytelling in Contemporary Cinema (Chichester: WileyBlackwell, 2009), and Hollywood Puzzle Films (London: Routledge, 2014).

${ }^{\mathrm{vi}}$ Charles Ramirez Berg, "A taxonomy of alternative plots in recent films: classifying the "Tarantino Effect", Film Criticism, vol. 31, no.1/2 (2006), pp. 5-61.

vii Ibid, p. 39.

viii Ibid, pp. 40-41.

ix The second strand of narratively complex films, according to Bordwell, is the 'puzzle film'. See The Way Hollywood Tells It, pp. 80-82.

${ }^{\mathrm{x}}$ David Bordwell, Poetics of Cinema (New York: Routledge, 2007), p. 245.

${ }^{x i}$ Bordwell, The Way Hollywood Tells It, p.96.

xii Bordwell, Poetics of Cinema, p. 198.

xiii Ibid, p. 197.

${ }^{\text {xiv }}$ Ibid, p. 199.

${ }^{\mathrm{xv}}$ Ibid, p. 193.

${ }^{\text {xvi }}$ Annette Kuhn, 'The classic narrative system', in Pam Cook (ed.), The Cinema Book: 3rd edition (London: British Film Institute, 2007), p. 45.

${ }^{x v i i}$ Noël Burch, Theory of Film Practice (Princeton, NJ: Princeton UP, 1981).

${ }^{\text {xviii }}$ Vivien Silvey, 'Not just ensemble films: six degrees, webs, multiplexity and the rise of network narratives', University of Edinburgh Postgraduate Journal of Culture and the Arts, vol. 8 (2009).

${ }^{\text {xix }}$ Peter Brooks, The Melodramatic Imagination (New Haven, CT: Yale University Press, 1976), p. 65.

${ }^{\mathrm{xx}}$ Maria del Mar Azcona Montoliú, 'A time to love and a time to die: desire and narrative structure in "21 Grams", Atlantis, vol. 31 no. 2 (2009); and also by the same author, The Multiprotagonist Film (Chichester: Wiley-Blackwell, 2010).

${ }^{x x i}$ See Brian Richardson, Unlikely Stories: Causality and the Nature of Modern Narrative (Newark, NJ: University of Delaware Press, 1997), pp. 15, 20, 62.

${ }_{\text {xxii Bordwell, Poetics of Cinema, p. } 214 .}$

xxiii Seymour Chatman, Coming to Terms: The Rhetoric of Narrative in Fiction and Film (Ithaca, NY: Cornell UP, 1990), p. 9.

xxiv Ibid, p. 47.

${ }^{x x v}$ Melanie Mitchell, Complexity: A Guided Tour (Oxford: Oxford University Press, 2009), p. 238.

${ }^{\text {xxvi }}$ Ibid. 
xxvii See Frederick J. Crosson and Kenneth M. Sayre (eds), Philosophy and Cybernetics: Essays Delivered to the Philosophical Institute for Artificial Intelligence at the University of Notre Dame (Notre Dame, IN: University of Notre Dame Press, 1967), p. 5.

xxviii Evan Smith, 'Thread structure: rewriting the Hollywood formula', Journal of Film and Video, vol. 51, no. 3/4 (2000), pp. 88-96; p. 90.

${ }^{x x i x}$ Stuart A. Kauffman, The Origins of Order: Self-organization and Selection in Evolution (New York: Oxford UP, 1993), p. 243.

${ }^{\mathrm{xxx}}$ Ashok Sengupta (ed), Chaos, Nonlinearity, Complexity: The Dynamical Paradigm of Nature (Berlin: Springer, 2006), p. 269.

xxxi Terrence W. Deacon, 'Emergence: the hole at the wheel's hub', in P. Clayton and P. Davies (eds.), The Re-emergence of Emergence: The Emergentist Hypothesis from Science to Religion (Oxford: Oxford UP, 2006), pp. 111-150; pp.121-122.

xxxii Bordwell, Poetics of Cinema, p. 212

xxxiii Ervin Laszlo, Introduction to Systems Philosophy: Towards a New Paradigm of

Contemporary Thought (New York: Gordon and Breach, 1972), p.250.

xxxiv Ibid.

${ }^{\text {xxxv }}$ Magoroh Maruyama, 'The second cybernetics: deviation amplifying mutual causal

processes', American Scientist, vol. 5, no. 2 (1963), pp. 164-179.

${ }^{x x x v i}$ Wendy Everett, 'Fractal films and the architecture of complexity', Studies in European

Cinema, vol. 2, no. 3 (2005), pp. 159-171; p.162.

xxxvii Maruyama ,'The second cybernetics', p.164.

xxxviii See Alain Barrat, Marc Barthelemy and Alessandro Vespigniani, Dynamical Processes on Complex Networks (Cambridge: Cambridge UP, 2008), pp. 97-98.

${ }^{x x x i x}$ Russ A. Marion, 'Complexity in organizations: a paradigm shift', in Sengupta (ed), Chaos, Nonlinearity, Complexity, pp. 247-269; p. 247.

${ }^{\mathrm{xl}}$ Aleksandr Yakovlevich Lerner, Fundamentals of Cybernetics (London: Chapman and Hall, 1972), p. 39.

xli Alexander Galloway and Eugene Thacker, The Exploit: A Theory of Networks (Minneapolis, MN: University of Minnesota Press, 2007), pp. 155-157.

xlii See 'TIFF: Burn After Reading with the Coen brothers, Brad Pitt, Tilda Swinton, and John Malkovich', Press conference during Toronto Film Festival 2008, reproduced by Jordan Riefe, The Dead Bolt.com,

<http://www.thedeadbolt.com/news/104984/burnafterreading_interview.php>. Accessed 26 January 2014.

xliii Ibid.

${ }^{\text {xliv }}$ See Eric Bonabeau, 'Agent-based modeling: Methods and techniques for simulating human systems', PNAS, vol. 99, no. 3 (2002), pp. 7280-7287.

${ }^{x l v}$ Pierre Marcenac, 'Modeling multiagent systems as self-organized critical systems', Proceedings from HICSS-31: 31 st Annual Hawaii International Conference on System Sciences, IEEE Computer Society Press, vol.5 (1998), pp. 86-95.

${ }^{\text {xlvi }}$ See Barrat, Barthélemy and Vespigniani, Dynamical Processes on Complex Networks.

xlvii Bordwell, Poetics of Cinema, p. 204. 